Article

\title{
Functionalization of Cyclodextrins with $N$-Hydroxyphthalimide Moiety: A New Class of Supramolecular Pro-Oxidant Organocatalysts
}

\section{Lucio Melone 1,2,3,*, Manuel Petroselli ${ }^{1,2}$, Nadia Pastori ${ }^{1,2}$ and Carlo Punta ${ }^{1,2}$}

1 Department of Chemistry, Materials, and Chemical Engineering "G. Natta"-Politecnico di Milano, Piazza Leonardo da Vinci 32, Milano I-20133, Italy;

E-Mails: manuel.petroselli@polimi.it (M.P.); nadia.pastori@polimi.it (N.P.); carlo.punta@polimi.it (C.P.)

2 INSTM, National Consortium of Materials Science and Technology, Local Unit Politecnico di Milano, Milano 20133, Italy

3 Università Telematica e-Campus, Via Isimbardi 10, Novedrate 22060, Italy

* Author to whom correspondence should be addressed; E-Mail: lucio.melone@polimi.it;

Tel.: +39-02-2399-3007; Fax: +39-02-2399-3180.

Academic Editor: Raquel P. Herrera

Received: 28 July 2015 / Accepted: 27 August 2015 / Published: 31 August 2015

\begin{abstract}
N$-hydroxyphthalimide (NHPI) is an organocatalyst for free-radical processes able to promote the aerobic oxidation of a wide range of organic substrates. In particular, NHPI can catalyze the hydroperoxidation of polyunsaturated fatty acids (PUFA). This property could be of interest for biological applications. This work reports the synthesis of two $\beta$-cyclodextrin derivatives (CD5 and CD6) having a different degree of methylation and bearing a NHPI moiety. These compounds, having different solubility in water, have been successfully tested for the hydroperoxidation of methyl linoleate, chosen as the PUFA model molecule.
\end{abstract}

Keywords: $N$-hydroxyphthalimide; cyclodextrin; polyunsaturated fatty acids; lipid peroxidation; reactive oxygen species; oxidative stress; cancer 


\section{Introduction}

Reactive oxygen species (ROS) are free radicals (FR) deriving from oxygen, produced as a normal part of metabolism within the mitochondria. External factors (i.e., smoking, UV-light exposition or environmental pollutants) can stimulate ROS production [1,2]. Increased levels of ROS may induce oxidative stress (OS), damaging proteins, DNA and RNA molecules, sugars and lipids, thus affecting negatively the cells structure and their functions. Different chronic diseases, such as Alzheimer's disease, diabetes mellitus, hypertension, and cancer in both animals and humans, are associated to the negative effects of the ROS cellular overproduction. With regard to cancer, there is a considerable body of experimental evidence on the tumorigenesis caused by the alteration of the redox status of the cells $[3,4]$. In order to reduce the OS, several antioxidants have been proposed as ROS scavengers [5], even if not all the studies pointed in the same direction regarding the beneficial effects of antioxidants to prevent the development of cancer [6,7]. A different strategy proposed in the last few years for the treatment of tumors relies on the promotion of the OS instead of its inhibition. In fact, compared to normal cells, cancer cells exhibit higher ROS levels, but they are also more sensitive to further increments of OS [8]. In other words, promoting the ROS production in tumoral tissues up to cytotoxic levels would selectively induce apoptosis of the cancer cells $[9,10]$. The development of new pro-oxidant molecules able to enhance the OS of cancer cells has, therefore, relevant scientific interest.

$N$-hydroxyphthalimide (NHPI) is an emerging organocatalyst capable of promoting free-radical aerobic oxidations by activating the hydrogen atom transfer processes via in situ generation of phthalimide- $N$-oxyl (PINO) radical (Scheme 1) [11-15]. NHPI has been extensively used for the oxidation of different organic compounds and has industrial relevance [16-22]. Due to its capability of catalyzing the peroxidation of lipids [23], NHPI could play a role in biomedicine as a pro-oxidant agent for cancer therapy. Unfortunately, the NHPI derivatives proposed in the literature for industrial use have been synthetized to be dissolved in liquid hydrocarbons, eventually using a co-solvent to increase their solubility [24,25]. Therefore, they are not suitable to be tested for the envisaged biological application. The synthesis of water-soluble derivatives bearing NHPI moieties could represent a valuable solution to tackle this problem. Moreover, the suitable choice of functional groups to be introduced into NHPI should also favor penetration of the cellular membrane, allowing the catalyst to manifest its pro-oxidant activity in the intracellular medium. Methyl- $\beta$-cyclodextrin (Me $\beta C D)$, is a highly water soluble cyclic heptasaccharide that has been proposed in cancer therapy due to its capability to deplete cholesterol from the membrane cells, thus enhancing the effects of anticancer drugs [26-28]. In the present work we describe the synthesis of two NHPI-functionalized Me $\beta C D$ derivatives, having different degrees of methylation, and we investigate their activities in the aerobic peroxidation of methyl linoleate, chosen as model molecule among the several polyunsaturated fatty acids (PUFA). Due to the synergistic action of the NHPI moieties, working as promoter of the oxidative stress, and Me $\beta C D$ acting as lipid raft disrupting agent, the proposed supramolecular vectors could represent potential pro-oxidant agents in biological systems. 


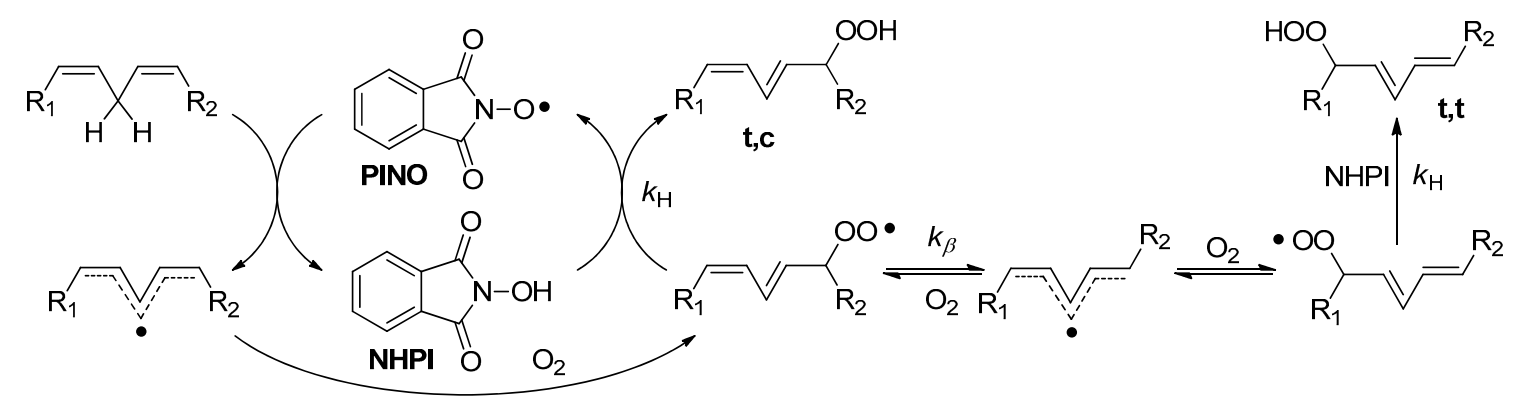

Scheme 1. NHPI-mediated peroxidation of a generic bis-allylic derivative.

\section{Results and Discussion}

\subsection{Synthesis and Characterization of NHPI-Functionalized MeßCD Derivatives}

Cyclodextrins (CDs) are macrocyclic oligosaccharides composed of 6, 7, or $8 \alpha$-[1-4]-linked $\alpha$-D-glucopyranose units ( $\alpha$-, $\beta$ - and $\gamma$-CD, respectively). These molecules have a truncated cone-shaped three-dimensional structure with an empty, hydrophobic, inner cavity. The hydroxyl groups of the anhydroglucose units are located both on the large rim (OH in position 2 and 3$)$ and on the small rim of the truncated cone ( $\mathrm{OH}$ in position 6). Among the three $\mathrm{CDs}, \beta \mathrm{CD}$ is the cheapest and most used, despite the fact that its solubility in water at $25^{\circ} \mathrm{C}\left(18.5 \mathrm{mg} \cdot \mathrm{mL}^{-1}\right)$ is lower than that of $\alpha \mathrm{CD}\left(145 \mathrm{mg} \cdot \mathrm{mL}^{-1}\right)$ and $\gamma \mathrm{CD}\left(232 \mathrm{mg} \cdot \mathrm{mL}^{-1}\right)$. The random methylation of the $\beta C D$ hydroxyl groups leads to derivatives that are more soluble. Indeed, commercially available $\mathrm{Me} \beta \mathrm{CD}$, with a degree of substitution (DS, average number of methyl groups per glucose repeat unit) equal to 1.8 , has a very high solubility in water $\left(>500 \mathrm{mg} \cdot \mathrm{L}^{-1}\right.$ at $25^{\circ} \mathrm{C}$ ). Me $\beta \mathrm{CD}$ has found several applications in the last few years, spanning from pharmaceutics and health care [29] to soil remediation [30]. The capability of Me $\beta C D$ to act as disruptor of lipid rafts selectively binding cholesterol is well documented [31], thus, offering a new tool for cancer therapy [26-28].

The synthesis of two $\beta C D$ derivatives at different degrees of methylation (CD5 and CD6) and bearing an NHPI moiety is outlined in Scheme 2. The methylation of CD2, the mono-azide- $\beta C D$ derivative, with two different amounts of methyl iodide, as described in the Experimental Section, afforded CD3 (permethylated) and CD4 (random methylated). Both molecules were characterized by ${ }^{1} \mathrm{H}-\mathrm{NMR}$, FT-IR (see Supplementary Materials for the spectra) and ESI-MS spectroscopies (see Figure 1a,b for CD3 and Figure 1c,d for CD4). In particular, the ESI-MS spectrum in the positive mode of CD3 shows the presence of peaks at $m / z 1462.7$ and $m / z 1478.7$ associated to $[\mathbf{C D 3}+\mathrm{Na}]^{+}$and $[\mathbf{C D 3}+\mathrm{K}]^{+}$, respectively.

The ESI-MS spectrum of CD4 is constituted by a more complex pattern of peaks in the range of $\mathrm{m} / \mathrm{z}$ 1250-1500. In particular, it shows the peak at $\mathrm{m} / \mathrm{z} 1462.7$ corresponding to the sodium adduct of the fully methylated product (analogous to CD3), and a sequence of peaks associated to the sodium adducts of the products with a lower number of methyl groups. Further details on the peaks distribution are reported in Table 1 of SI. The calculation of the average molecular weight ( $\left.\bar{M}_{W}\right)$ and the DS of CD4 were performed using Equations (SI1) and (SI2) in the Supplementary Materials providing the following values: $\bar{M}_{W}=1355 \mathrm{~g} \mathrm{~mol}^{-1}$ and $D S=2.0$. A similar $D S$ value (1.91) was obtained from the ${ }^{1} \mathrm{H}-\mathrm{NMR}$ spectrum of CD4 in $\mathrm{D}_{2} \mathrm{O}$. 


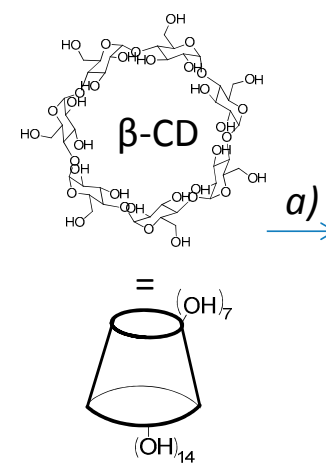

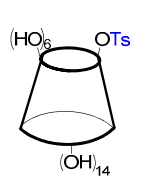

CD1

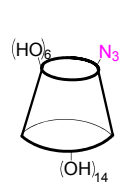

CD2

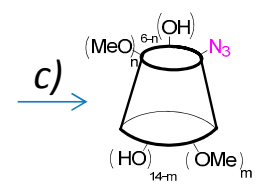

CD3 $(m+n=20)$

CD4 $(m+n<20)$
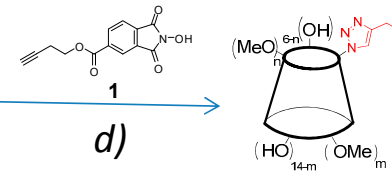

$\operatorname{CD5}(m+n=20)$

CD6 $(m+n<20)$

Scheme 2. Synthetic scheme. (a) TsCl, $\mathrm{NaOH}$ (aq) $0.4 \mathrm{M}, 0{ }^{\circ} \mathrm{C} 8 \mathrm{~h}$; (b) $\mathrm{NaN}_{3}, \mathrm{DMSO}, 90{ }^{\circ} \mathrm{C}$, 12 h; (c) dry DMF, $\mathrm{NaH}, \mathrm{CH}_{3} \mathrm{I}, 0{ }^{\circ} \mathrm{C}, 8 \mathrm{~h}$; (d) THF: $\mathrm{H}_{2} \mathrm{O}=1: 1(v: v)$, 1, L-ascorbic acid, $\mathrm{Cu}^{2+}$, $40{ }^{\circ} \mathrm{C}, 24 \mathrm{~h}, \mathrm{~N}_{2}$ atmosphere.

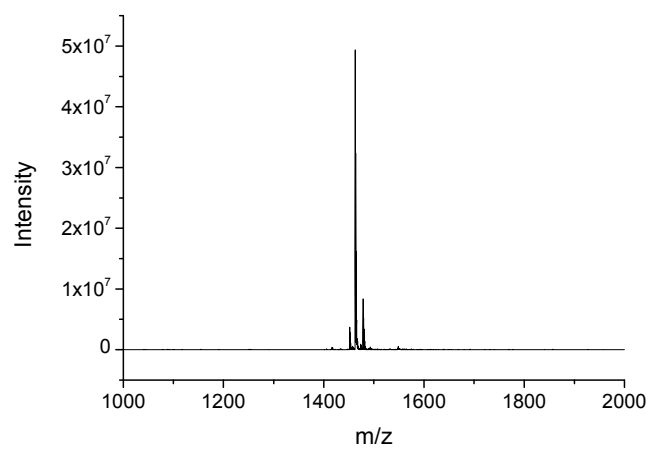

(a)

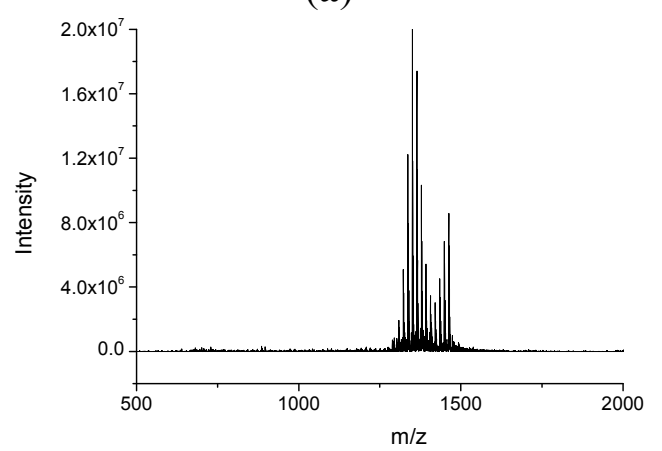

(c)

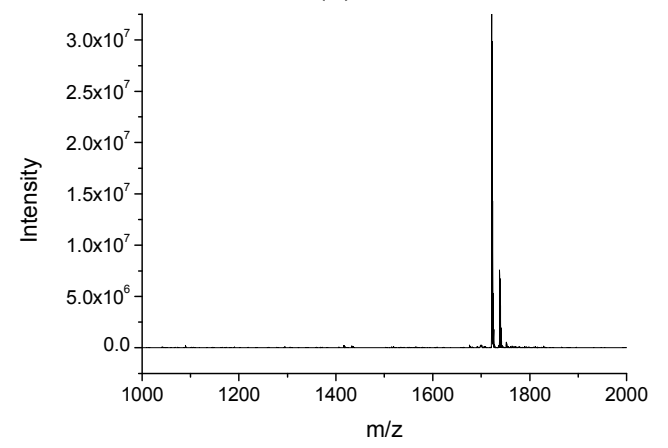

(e)

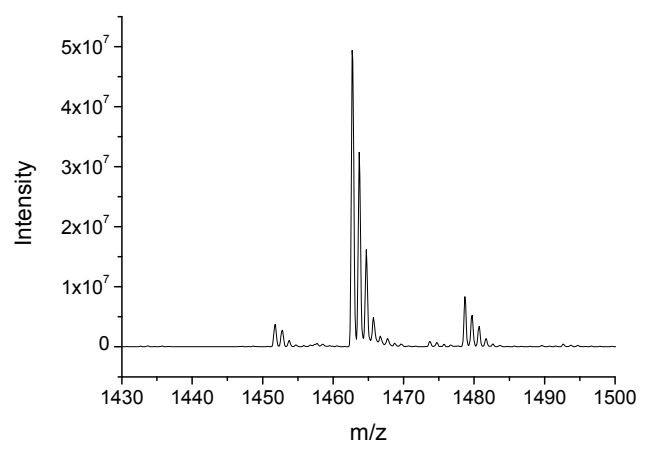

(b)

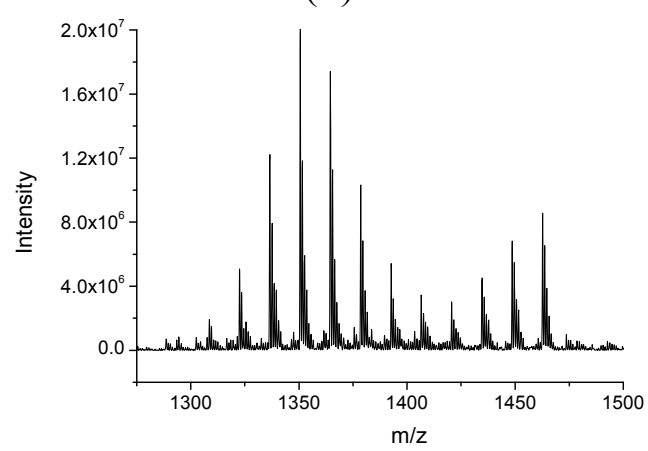

(d)

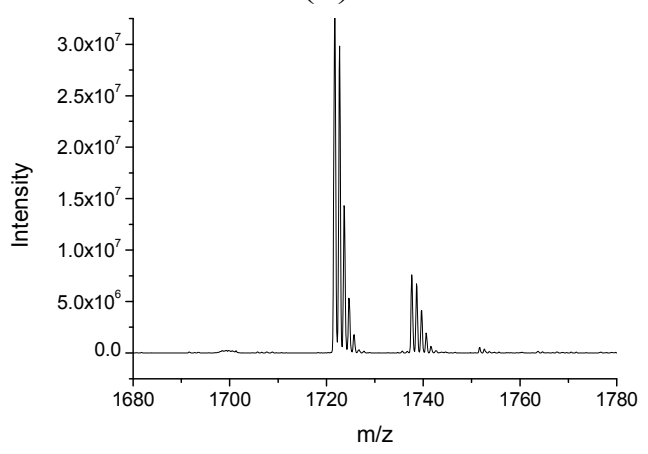

(f)

Figure 1. Cont. 


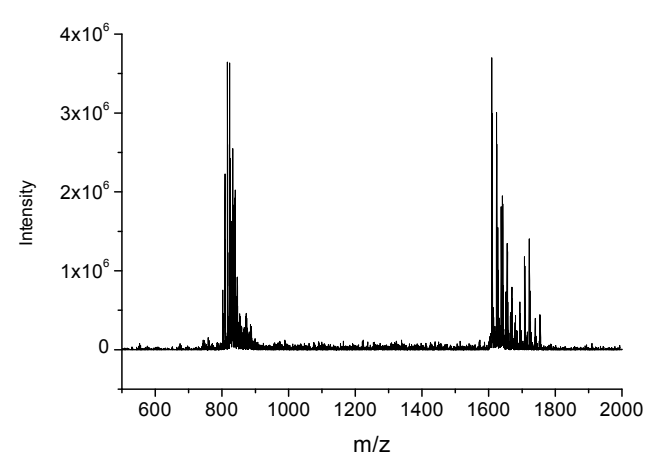

(g)

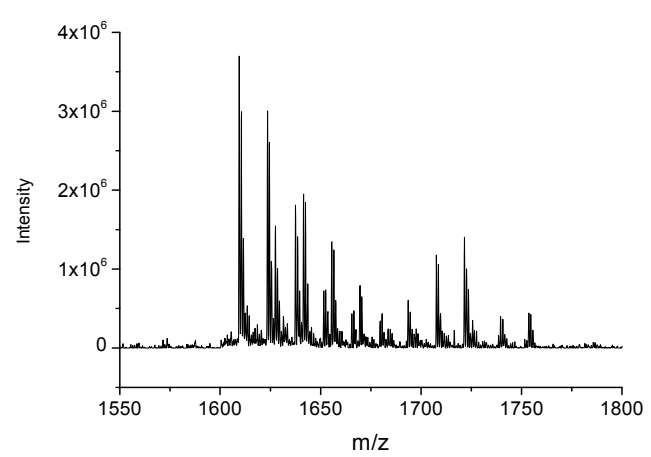

(h)

Figure 1. ESI-MS spectra in positive mode of CD3 (a,b); CD4 (c,d); CD5 (e,f); CD6 (g,h).

Table 1. Methyl linoleate oxidation under $\mathrm{O}_{2}(1 \mathrm{~atm})$ at $28^{\circ} \mathrm{C}$. Conditions: $5 \mathrm{mmol}$ of methyl linoleate, catalyst ( $2 \% \mathrm{~mol}), 1.5 \mathrm{~mL}$ acetonitrile, $24 \mathrm{~h}$.

\begin{tabular}{ccccc}
\hline \multirow{2}{*}{ Entry } & \multirow{2}{*}{ Catalyst } & \multirow{2}{*}{ Conversion $^{\mathbf{1}} \mathbf{( \% )}$} & \multicolumn{2}{c}{ Selectivity $^{\mathbf{2}} \mathbf{( \% )}$} \\
\cline { 3 - 5 } & & 5.4 & $\mathbf{T C}$ & $\mathbf{T T}$ \\
\hline 1 & & 42.7 & 62 & 38 \\
2 & NHPI & 54.7 & 50.5 & 50.5 \\
3 & CD5 & 48.0 & 53.8 & 49.4 \\
4 & CD6 &
\end{tabular}

${ }^{1}$ See Equation (S3) in the Supplementary Materials. ${ }^{2}$ See Equation (S4) in the Supplementary Materials.

The click reaction between CD3 or CD4 with the derivative 1 (but-3-yn-1-yl 2-hydroxy-1,3dioxoisoindoline-5-carboxylate) to afford CD5 and CD6, respectively, was carried out in THF as solvent in the presence of $\mathrm{L}$-ascorbic $\mathrm{acid} / \mathrm{Cu}^{2}{ }^{+}$catalyst at room temperature and under a nitrogen atmosphere. The complete disappearance of the azide peak at $2102 \mathrm{~cm}^{-1}$ in the FT-IR spectra of both the derivatives (see Figure S12) was obtained in $48 \mathrm{~h}$ of reaction time. The FT-IR spectra of CD5 and CD6 confirmed the presence of a peak at $1734 \mathrm{~cm}^{-1}$, likely associated to the $\mathrm{C}=\mathrm{O}$ stretching of the ester and the imide groups. The ${ }^{1} \mathrm{H}-\mathrm{NMR}$ spectrum of $\mathbf{C D 5}$ obtained in acetone- $d_{6}$ confirmed the presence of four peaks in the range between 7.6 and $8.6 \mathrm{ppm}$. Three of them are attributed to the NHPI aromatic ring protons (7.98 ppm, $\mathrm{d}, 1 \mathrm{H} ; 8.33, \mathrm{~s}, 1 \mathrm{H} ; 8.44 \mathrm{ppm}, \mathrm{d}, 1 \mathrm{H}$ ) and one is associated to the proton of the triazole ring (7.86 ppm, s, 1H). The NO-H proton is visible as broad singlet at $9.92 \mathrm{ppm}$. The anomeric protons give a multiplet in the range 5.05-5.40 ppm $(7 \mathrm{H})$ while the $\mathrm{H}-6^{\prime}$ protons $(2 \mathrm{H})$ give a doublet of doublets in the range of 4.90-5.00 ppm. The triplet at $4.68 \mathrm{ppm}$ is attributed to the $\mathrm{CH}_{2}$ adjacent to the ester group. A complex pattern of overlapping peaks in the range $2.90-4.20 \mathrm{ppm}$ comprises the signals associated to the protons of the anhydroglucose units in the positions 2, 3, 4, 5 and 6, the $\mathrm{CH}_{3}$ signals and the signal of $\mathrm{CH}_{2}$ adjacent to the triazole ring (102H in total). The ESI-MS spectrum of CD5 (Figure 1e,f) shows the presence of an intense peak at $m / z 1721.7$ associated to $[\mathbf{C D 5}+\mathrm{Na}]^{+}$with the presence of two smaller peaks at $m / z 1699.7\left([\mathbf{C D 5}+\mathrm{H}]^{+}\right)$and $m / z 1737.7\left([\mathbf{C D 5}+\mathrm{K}]^{+}\right)$. The ${ }^{1} \mathrm{H}-\mathrm{NMR}$ spectrum of CD6 was obtained in DMSO- $d_{6}$ with the addition of few drops of $\mathrm{D}_{2} \mathrm{O}$ in order to simplify its interpretation, which is similar to that of CD5.

Interestingly, the ESI-MS spectrum of CD6 shows the presence of two sets of peaks (in the ranges $m / z$ 1700-1780 and $m / z$ 800-900). The detailed analysis of the first set of peaks (not reported) evidences 
the signals associated to the single charged sodium adducts of products at different level of methylation, with a distribution similar to the one of CD4. The second set of peaks is, instead, ascribed to the doubled charged sodium adducts. For comparison, the ESI-MS of CD6 in negative mode (see Figure S11) shows the presence of only one set of peaks in the range $m / z \quad 1520-1710$ attributed to $[\mathbf{C D 6}-\mathrm{H}]^{-}$at different levels of methylation. The average molecular weight of CD6 $\left(1614 \mathrm{~g} \cdot \mathrm{mol}^{-1}\right)$ was calculated from the one of CD4.

The two derivatives, CD5 and CD6, have significantly different water solubilities. CD6 is very soluble in water. At $28{ }^{\circ} \mathrm{C}, 71.6 \mathrm{mg}$ of $\mathbf{C D 6}$ were completely dissolved in only $76.5 \mathrm{mg}$ of water obtaining a transparent viscous liquid. Due to the increased viscosity of the solution, no further addition of CD6 was carried out. Therefore, CD6 solubility is expected to exceed $950 \mathrm{~g} \cdot \mathrm{L}^{-1}$, a value significantly higher than that related to the solubility in water of simple NHPI $\left(50.5 \mathrm{~g} \cdot \mathrm{L}^{-1}\right)$ [32]. On the contrary, CD5 has a lower, but not negligible, solubility, as expected on the basis of its molecular structure. In fact, only $16.0 \mathrm{mg}$ could be dissolved into $860 \mathrm{mg}$ of water, leading to a solubility value of just $18.8 \mathrm{~g} \cdot \mathrm{L}^{-1}$ at $28{ }^{\circ} \mathrm{C}$. These results confirm the versatility of the proposed systems, as it is possible to modulate the hydrophilicity/hydrophobicity of the organocatalysts by monitoring the methylation of the cavitand. This aspect has direct effects on the solubility of the NHPI derivative, but also allows to better-fit the structure chemistry for a high permeability of the cellular membrane by the supramolecular pro-oxidant.

\subsection{Catalytic Activity}

PUFA, the essential components of cellular membranes, are particularly prone to peroxidation, and, for this reason, methyl linoleate has been chosen as a representative substrate for testing the catalytic activity of CD5 and CD6 pro-oxidants. The high reactivity of these lipids towards oxygen is associated to the low bond dissociation energy (BDE) of the $\mathrm{C}-\mathrm{H}$ bonds in the bis-allylic position ( $\sim 73 \mathrm{Kcal} / \mathrm{mol})$ [33], which favors hydrogen atom abstraction from peroxyl radicals. Primary products of peroxidation are two trans/cis hydroperoxides, deriving from the hydrogen substitution with oxygen at the 13 and 9 positions, and two trans/trans analogues, with a more stable geometry, formed via $\beta$-fragmentation of the intermediate peroxyl radicals (Scheme 1). In the absence of hydrogen donors, the mechanism may also include fragmentation and cyclization reactions, leading to the formation of secondary products.

In the presence of NHPI, the reaction run faster and with higher selectivity in hydroperoxides [23]. In fact, hydrogen atom abstraction from bis-allylic position by PINO radical is thermodynamically favored, being that the $\mathrm{O}-\mathrm{H}$ BDE value in the corresponding NHPI is significantly higher $(88.1 \mathrm{Kcal} / \mathrm{mol})$ [34]. Moreover, NHPI traps peroxyl radicals before they undergo secondary reactions, limiting the formation of products uniquely to hydroperoxides (Scheme 1).

The methyl linoleate peroxidation experiments were carried out using CD5 or CD6 as catalysts, in the absence of an initiator and in presence of the minimum amount of acetonitrile required for obtaining a homogeneous mixture. For comparison, the same experiments were also carried out using NHPI. The identification of the peroxidation products and their quantification were obtained by ${ }^{1} \mathrm{H}-\mathrm{NMR}$ spectroscopy, following the paper of Pajunen et al. [35]. This technique is simple, fast, and reliable, and represents a valid alternative to the more cumbersome HPLC analysis protocol [23]. Further details can be found in the Supplementary Materials. 
Different from HPLC analysis, ${ }^{1} \mathrm{H}-\mathrm{NMR}$ spectroscopy does not allow to distinguish the hydroperoxides $\boldsymbol{\alpha}$ and $\boldsymbol{\beta}$ or the hydroperoxides $\boldsymbol{\gamma}$ and $\boldsymbol{\delta}$ (see Figure 2). Therefore, $\boldsymbol{\alpha}$ and $\boldsymbol{\beta}$ will be simply identified as "trans-trans" (TT) hydroperoxides, while $\boldsymbol{\gamma}$ and $\boldsymbol{\delta}$ will be identified as "trans-cis" (TC) hydroperoxides. However, this aspect is not crucial for the scope of this work. Indeed, following the initial motivation of the work, oriented to the proposal of new pro-oxidant catalysts, the scope of the paper is aimed at demonstrating the effective capability of CD5 and CD6 in catalyzing a lipid peroxidation process without any particular interest for the regio- and stereoselectivity. Table 1 summarizes the experimental results, providing the methyl linoleate conversion and the selectivity of the oxidative process to TC and TT hydroperoxides. In the absence of catalyst, the autoxidation process led to a very low conversion (5.4\%, entry 1). In the presence of CD5 (entry 3) and CD6 (entry 4), the conversions were significantly higher and comparable with the value associated to NHPI (entry 2).

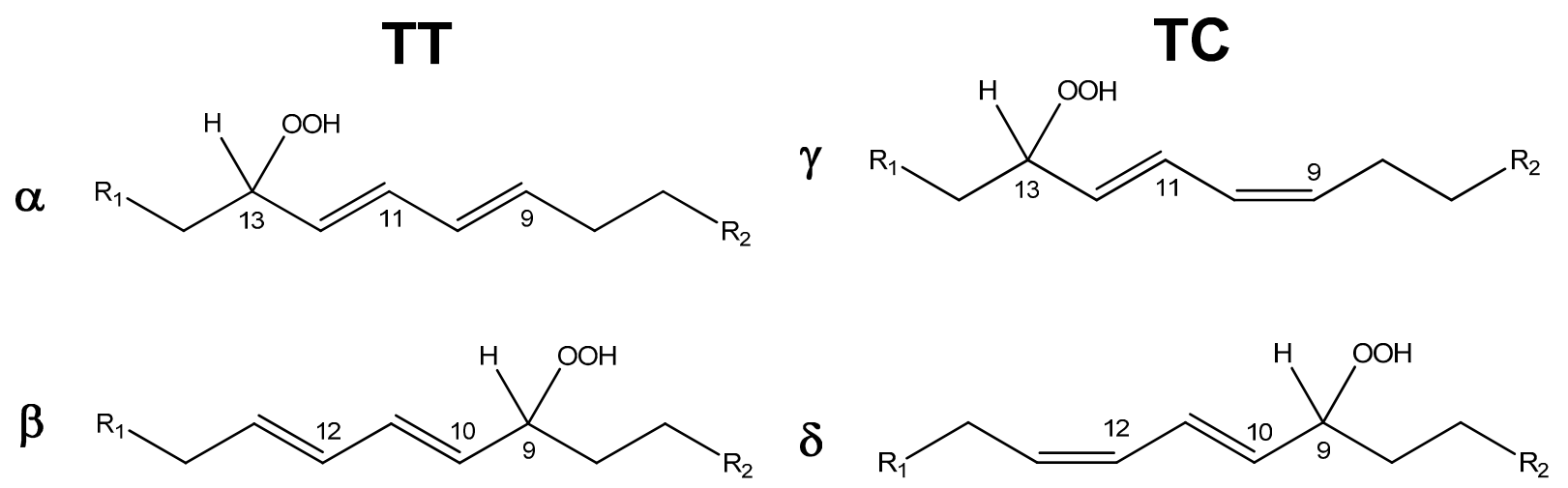

Figure 2. Different hydroperoxides formed during the aerobic oxidation of methyl linoleate catalyzed by CD-NHPI derivatives. $\boldsymbol{\alpha}$ : Methyl 13-(R,S)-hydroperoxy-9-trans, 11-trans-octadecadienoate; $\boldsymbol{\beta}$ : Methyl 9-(R,S)-hydroperoxy-10-trans,12-trans-octadecadienoate; $\gamma$ : Methyl 13-(R,S)-hydroperoxy-9-cis,11-trans-octadecadienoate; $\delta$ : Methyl 9-(R,S)hydroperoxy-10-trans, 12-cis-octadecadienoate. $\mathrm{R}_{1}=\mathrm{CH}_{3}\left(\mathrm{CH}_{2}\right)_{3} ; \mathrm{R}_{2}=\left(\mathrm{CH}_{2}\right)_{5} \mathrm{CO}_{2} \mathrm{CH}_{3}$.

\section{Experimental Section}

\subsection{General}

$\beta$-cyclodextrin $(\beta C D)$ and other reagents and solvents were commercially available and used as received unless otherwise stated. 6A-O-p-toluenesulfonyl- $\beta C D$ (CD1) was obtained according to a published procedure [36] with minor modifications. The corresponding monoazide derivative (CD2) was obtained reacting CD1 with an excess of $\mathrm{NaN}_{3}$ in DMSO at $90{ }^{\circ} \mathrm{C}$ overnight. The methylation of CD2 in order to obtain the derivatives CD3 and CD4 was performed in anhydrous DMF (60 mL) following the procedure similar to the one described by Muderawan et al. [37]. All the details are reported in the Supplementary Materials.

${ }^{1} \mathrm{H}-\mathrm{NMR}$ spectra of the products were recorded at $305 \mathrm{~K}$ with a Bruker Avance-500 $\mathrm{MHz} \mathrm{NMR}$ spectrometer (Bruker, Billerica, MA, USA). The FT-IR solid phase spectra of the powdered sample with infrared grade $\mathrm{KBr}$ were recorded using a Varian 640-IR spectrometer (Varian, Palo Alto, CA, USA). ESI-MS mass spectra were collected on a Bruker Esquire 3000+ with electrospray ionization source and 
ion-trap detector. The samples were analyzed by direct infusion of suitable solutions (methanol) in the spectrometer source.

\subsection{Synthesis of the Derivative 1 (But-3-yn-1-yl 2-hydroxy-1,3-dioxoisoindoline-5-carboxylate)}

Trimellitic anhydride chloride (4.21 g, $20 \mathrm{mmol}$ ) was dissolved in $40 \mathrm{~mL}$ of anhydrous THF with $3 \mathrm{~mL}$ of anhydrous pyridine. Then, $20 \mathrm{~mL}$ of a solution of 3-butyn-1-ol (1.40 g, $20 \mathrm{mmol})$ in anhydrous THF were added dropwise over $1 \mathrm{~h}$ under stirring at $0{ }^{\circ} \mathrm{C}$. The mixture was kept at $0{ }^{\circ} \mathrm{C}$ for $6 \mathrm{~h}$ and then at room temperature overnight. The white precipitate formed during the reaction was removed by filtration on paper while the solution was concentrated under vacuum. An excess of hydroxylamine hydrochloride (30 mmol, $2.09 \mathrm{~g}$ ) was added to the thus-obtained syrup after diluting it with $25 \mathrm{~mL}$ of anhydrous pyridine. The mixture was stirred at room temperature for $30 \mathrm{~min}$ and then under reflux for $1 \mathrm{~h}$ in a microwave reactor with the automatic control of the temperature (Micro-SYNTH Labstation-Milestone Inc., Shelton, CT, USA). The solvent was removed under vacuum, obtaining a bright orange sticky solid that was finally washed with $\mathrm{HCl}(0.1 \mathrm{M})$ in a ice bath until complete removal of the residual pyridine. The procedure provided, in quantitative yield, an off-white solid that was used for the preparation of CD5 and CD6 without further purification. ${ }^{1} \mathrm{H}-\mathrm{NMR}\left(400 \mathrm{MHz}, \mathrm{DMSO}-d_{6}\right): \delta=10.95(\mathrm{~s}, 1 \mathrm{H}), 8.36(\mathrm{~d}$, $1 \mathrm{H}), 8.20(\mathrm{~s}, 1 \mathrm{H}), 7.98(\mathrm{~d}, 1 \mathrm{H}), 4.41(\mathrm{t}, 2 \mathrm{H}, J=6.57 \mathrm{~Hz}), 2.86(\mathrm{t}, 1 \mathrm{H}, J=2.69 \mathrm{~Hz}), 2.704\left(\mathrm{td}, 2 \mathrm{H}, J_{1}=6.57\right.$ $\left.\mathrm{Hz}, J_{2}=2.69 \mathrm{~Hz}\right),{ }^{13} \mathrm{C}-\mathrm{NMR}\left(100 \mathrm{MHz}, \mathrm{DMSO}-d_{6}\right): 164.42,163.62,163.60,135.70,135.13,133.05$, $129.79,123.87,123.15,81.14,72.95,63.81,18.77$.

\subsection{Synthesis of CD5 Derivative}

CD3 (1.86g, $1.29 \mathrm{mmol})$ and $1(670 \mathrm{mg}, 2.58 \mathrm{mmol})$ were dissolved in $25 \mathrm{~mL}$ of THF under slow $\mathrm{N}_{2}$ flow. Then, $1 \mathrm{~mL}$ of an aqueous solution of L-ascorbic acid $(88.1 \mathrm{mg}, 0.5 \mathrm{mmol}), \mathrm{CuSO}_{4} \times 5 \mathrm{H}_{2} \mathrm{O}(62.4 \mathrm{mg}$, $0.25 \mathrm{mmol})$ and $\mathrm{Et}_{3} \mathrm{~N}$ (2 droplets) were added to the reaction mixture. The system was stirred at room temperature for $48 \mathrm{~h}$ under $\mathrm{N}_{2}$ atmosphere. After evaporating the solvent, the solid was transferred into a separatory funnel and extracted with EtOAc $(3 \times 100 \mathrm{~mL})$. The organic phases, containing both CD5 and the excess of $\mathbf{1}$, were collected together, dried onto anhydrous $\mathrm{Na}_{2} \mathrm{SO}_{4}$ and concentrated under vacuum. The corresponding syrup was transferred onto a silica gel column and eluted with Et $t_{2} \mathrm{O}$. After the complete removal of the derivative 1, the product CD5 was collected by eluting the column with a $\mathrm{CHCl}_{3}: \mathrm{MeOH}(10: 1)$ solution (about $300 \mathrm{~mL}$ ). Finally, the orange colored organic phase was washed with $\mathrm{HCl} 0.1 \mathrm{M}$ in a separatory funnel, dried onto anhydrous $\mathrm{Na}_{2} \mathrm{SO}_{4}$ and evaporated under vacuum, obtaining a pale yellow solid $(2.05 \mathrm{~g}, \approx 93.5 \%$ yield $)$.

\subsection{Synthesis of CD6 Derivative}

CD6 was obtained following a procedure similar to CD5 from $678 \mathrm{mg}$ of CD4 (0.5 mmol) and $520 \mathrm{mg}(2.00 \mathrm{mmol})$ of $\mathbf{1}$ dissolved in $15 \mathrm{~mL}$ of THF. The purification on silica gel column was carried out, first eluting with $\mathrm{Et}_{2} \mathrm{O}$ in order to remove the residual 1, and then with $\mathrm{MeOH}$ to recover the product. $\mathrm{MeOH}$ was almost completely evaporated under vacuum. The mixture was diluted in $\mathrm{CHCl}_{3}(150 \mathrm{~mL})$ and washed with $\mathrm{HCl} 0.1 \mathrm{M}$ in a separatory funnel. The organic phase was dried onto anhydrous $\mathrm{Na}_{2} \mathrm{SO}_{4}$ and finally evaporated under vacuum, recovering a pale yellow solid (820 mg, 50.8\%). 


\subsection{General Procedure for the Methyl Linoleate Aerobic Peroxidation}

The catalyst (CD5 (172.2 mg, $0.1 \mathrm{mmol})$ or CD6 (161.4 mg, $0.1 \mathrm{mmol}$ ) or NHPI (16.3 mg, $0.1 \mathrm{mmol})$ ) was dissolved in $1.5 \mathrm{~mL}$ of acetonitrile with $5 \mathrm{mmol}(1.472 \mathrm{~g})$ of methyl linoleate. The solution was stirred under $\mathrm{O}_{2}(1 \mathrm{~atm})$ at $28{ }^{\circ} \mathrm{C}$ for $24 \mathrm{~h}$. Three hundred microliters of this solution were loaded onto a short silica gel column and eluted with hexane:ethyl acetate 1:1 (about $3 \mathrm{~mL}$ ) in order to remove the catalyst. The eluent was evaporated under flux of nitrogen in about $1 \mathrm{~h}$ at $28{ }^{\circ} \mathrm{C}$ obtaining a transparent oil that was analyzed by ${ }^{1} \mathrm{H}-\mathrm{NMR}$ spectroscopy. Further details on the characterization are reported in the Supplementary Materials.

\section{Conclusions}

The synthesis of two new supramolecular pro-oxidant organocatalysts, CD5 and CD6, has been reported. The synthetic approach is based on the functionalization of permethylated and random methylated cyclodextrins with NHPI moieties by a click chemistry approach. Final products, fully characterized by NMR, IR and ESI-MS spectroscopic techniques, showed a completely different solubility in water medium, revealing how the cyclodextrin methylation degree can be an ideal tool to modulate catalyst solubility. Moreover, the linking of NHPI to methylated cyclodextrin cavitands, which have a higher affinity with cellular membranes, opens the route for the use of these catalysts as possible pro-oxidant agents in cancer therapy. For this reason, the catalytic activity of the new systems has been successfully verified in the oxidation of methyl linoleate, chosen as a representative sample as the corresponding cholesteryl ester as a key component of lipid membranes. Both the catalysts showed a catalytic efficiency analogous to that of simple NHPI, confirming how cyclodextrin functionalization does not affect NHPI reactivity. As expected, the oxidation process is selective in the formation of the corresponding hydroperoxides, without leading to the formation of secondary products. Further studies will be conducted in order to verify the possible catalytic activity of these systems in biological mediums.

\section{Supplementary Materials}

Supplementary materials can be accessed at: http:/www.mdpi.com/1420-3049/20/09/15881/s1.

\section{Acknowledgments}

MIUR is acknowledged for financial support (PRIN 2010-2011, PROxi project 2010PFLRJR_005).

\section{Author Contributions}

M.P. and N.P. carried out the oxidation experiments and analyzed the data. C.P. analyzed the data and co-wrote the paper. L.M. performed the synthesis, designed the experiments, analyzed the data and wrote the paper.

\section{Conflicts of Interest}

The authors declare no conflict of interest. 


\section{References}

1. Verbon, E.H.; Post, J.A.; Boonstra, J. The influence of reactive oxygen species on cell cycle progression in mammalian cells. Gene 2012, 511, 1-6.

2. Garber, K. Biochemistry: A radical treatment. Nature 2012, 489, S4-S6.

3. Waris, G.; Ahsan, H. Reactive oxygen species: Role in the development of cancer and various chronic conditions. J. Carcinog. 2006, 5, 14, doi:10.1186/1477-3163-5-14.

4. Liou, G.Y.; Storz, P. Reactive oxygen species in cancer. Free Radic. Res. 2010, 44, 479-496.

5. Valko, M.; Rhodes, C.J.; Moncol, J.; Izakovic, M.; Mazur, M. Free radicals, metals and antioxidants in oxidative stress-induced cancer. Chem. Biol. Interact. 2006, 160, 1-40.

6. Perera, R.M.; Bardeesy, N. Cancer: When antioxidants are bad. Nature 2011, 475, 43-44.

7. Chandel, N.S.; Tuveson, D.A. The Promise and Perils of Antioxidants for Cancer Patients. N. Engl. J. Med. 2014, 371, 177-178.

8. Glasauer, A.; Chandel, N.S. Targeting antioxidants for cancer therapy. Biochem. Pharmacol. 2014, 92, 90-101.

9. Raj, L.; Ide, T.; Gurkar, A.U.; Foley, M.; Schenone, M.; Li, X.; Tolliday, N.J.; Golub, T.R.; Carr, S.A.; Shamji, A.F.; et al. Selective killing of cancer cells by a small molecule targeting the stress response to ROS. Nature 2011, 475, 231-234.

10. Noh, J.; Kwon, B.; Han, E.; Park, M.; Yang, W.; Cho, W.; Yoo, W.; Khang, G.; Lee, D. Amplification of oxidative stress by a dual stimuli-responsive hybrid drug enhances cancer cell death. Nat. Commun. 2015, 6, 6907, doi:10.1038/ncomms7907.

11. Recupero F.; Punta, C. Free Radical Functionalization of Organic Compounds Catalyzed by N-Hydroxyphthalimide. Chem. Rev. 2007, 107, 3800-3842.

12. Galli, C.; Gentili, P.; Lanzalunga, O. Hydrogen Abstraction and Electron Transfer with Aminoxyl Radicals: Synthetic and Mechanistic Issues. Angew. Chem. Int. Ed. 2008, 47, 4790-4796.

13. Coseri, S. Phthalimide- $N$-oxyl (PINO) radical, a powerful catalytic agent: Its generation and versatility towards various organic substrates. Catal. Rev. 2009, 51, 218-292.

14. Melone, L.; Punta, C. Metal-free aerobic oxidations mediated by $N$-hydroxyphthalimide. A concise review. Beilstein J. Org. Chem. 2013, 9, 1296-1310.

15. Wertz, S.; Studer, A. Nitroxide-catalyzed transition-metal-free aerobic oxidation processes. Green Chem. 2013, 15, 3116-3134.

16. Melone, L.; Gambarotti, C.; Prosperini, S.; Pastori, N.; Recupero, F.; Punta, C. Hydroperoxidation of tertiary alkylaromatics catalyzed by $\mathrm{N}$-Hydroxyphthalimide and aldehydes under mild conditions. Adv. Synth. Catal. 2011, 353, 147-154.

17. Melone, L.; Prosperini, S.; Gambarotti, C.; Pastori, N.; Recupero F.; Punta, C. Selective catalytic aerobic oxidation of substituted ethylbenzenes under mild conditions. J. Mol. Catal. A 2012, 355, $155-160$.

18. Melone, L.; Franchi, P.; Lucarini M.; Punta, C. Sunlight induced oxidative photoactivation of $N$-hydroxyphthalimide mediated by naphthalene imides. Adv. Synth. Catal. 2013, 355, 3210-3220.

19. Liu, G.; Tang, R.; Wang, Z. Metal-Free Allylic Oxidation with Molecular Oxygen Catalyzed by g- ${ }_{3} \mathrm{~N}_{4}$ and $\mathrm{N}$-Hydroxyphthalimide. Catal. Lett. 2014, 144, 717-722. 
20. Chen, K.; Zhang, P.; Wang, Y.; Li, H. Metal-free allylic/benzylic oxidation strategies with molecular oxygen: Recent advances and future prospects. Green Chem. 2014, 16, 2344-2374.

21. Chen, K.; Jia, L.; Wang, C.; Yao, J.; Chen, Z.; Li, H. Theoretical Design of Multi-Nitroxyl Organocatalysts with Enhanced Reactivity for Aerobic Oxidation. ChemPhysChem 2014, 15, 1673-1680.

22. Zhao, Q.; Chen, K.; Zhang, W.; Yao, J.; Li, H. Efficient metal-free oxidation of ethylbenzene with molecular oxygen utilizing the synergistic combination of NHPI analogues. J. Mol. Catal. A Chem. 2015, 402, 79-82.

23. Punta, C.; Rector, C.L.; Porter, N.A. Peroxidation of Polyunsaturated Fatty Acid Methyl Esters Catalyzed by $N$-Methyl Benzohydroxamic Acid: A New and Convenient Method for Selective Synthesis of Hydroperoxides and Alcohols. Chem. Res. Toxicol. 2005, 18, 349-356.

24. Melone, L.; Prosperini, S.; Ercole, G.; Pastori, N.; Punta, C. Is it possible to implement $N$-hydroxyphthalimide homogeneous catalysis for industrial applications? A case study of cumene aerobic oxidation. J. Chem. Technol. Biotechnol. 2014, 89, 1370-1378.

25. Petroselli, M.; Franchi, P.; Lucarini, M.; Punta, C.; Melone, L. Aerobic Oxidation of Alkylaromatics using a Lipophilic $N$-Hydroxyphthalimide: Overcoming the Industrial Limit of Catalyst Solubility. ChemSusChem 2014, 7, 2695-2703.

26. Gotoh, K.; Kariya, R.; Alam, M.; Matsuda, K.; Hattori, S.; Maeda, Y.; Motoyama, K.; Kojima, A.; Arima, H.; Okada, S. The antitumor effects of methyl- $\beta$-cyclodextrin against primary effusion lymphoma via the depletion of cholesterol from lipid rafts. Biochem. Biophys. Res. Commun. 2014, 455, 285-289.

27. Mohammad, N.; Malvi, P.; Singh Meena, A.; Vikram Singh, S.; Chaube, B.; Vannuruswamy, G.; Kulkarni, M.J.; Bhat, M.K. Cholesterol depletion by methyl- $\beta$-cyclodextrin augments tamoxifen induced cell death by enhancing its uptake in melanoma. Mol. Cancer 2014, 13, 204, doi:10.1186/1476-4598-13-204.

28. Hryniewicz-Jankowska, A.; Augoff, K.; Biernatowska, A.; Podkalicka, J.; Sikorski, A.F. Membrane rafts as a novel target in cancer therapy. Biochim. Biophys. Acta 2014, 1845, 155-165.

29. Loftsson, T.; Brewster, M.E. Cyclodextrins as functional excipients: Methods to enhance complexation efficiency. J. Pharm. Sci. 2012, 101, 3019-3032.

30. Flaherty, R.J.; Nshime, B.; de LaMarre, M.; de Jong, S.; Scott, P.; Lantz, A.W. Cyclodextrins as complexation and extraction agents for pesticides from contaminated soil. Chemosphere 2013, 91, 912-920.

31. Tekpli, X.; Holme, J.A.; Sergent, O.; Lagadic-Gossmann, D. Role for membrane remodeling in cell death: Implication for health and disease. Toxicology 2013, 304, 141-157.

32. Gambarotti, C.; Punta, C.; Recupero, F. Encyclopedia of Reagents for Organic Synthesis; John Wiley \& Sons: Weinheim, Germany, 2005.

33. Pratt, D.A.; Mills, J.H.; Porter, N.A. Theoretical calculations of carbon-oxygen bond dissociation enthalpies of peroxyl radicals formed in the autoxidation of lipids. J. Am. Chem. Soc. 2003, 125, 5801-5810.

34. Amorati, R.; Lucarini, M.; Mugnaini, M.; Pedulli, G.F.; Minisci, F.; Recupero, F.; Fontana, F.; Astolfi, P.; Greci, L. Hydroxylamines as oxidation catalysts: Thermochemical and kinetic studies. J. Org. Chem. 2003, 68, 1747-1754. 
35. Pajunen, T.I.; Koskela, H.; Hase, T.; Hopia, A. NMR properties of conjugated linoleic acid (CLA) methyl ester hydroperoxides. Chem. Phys. Lipids 2008, 154, 105-114.

36. Brady, B.; Lynam, N.; O’Sullivan, T.; Ahern, C.; Darcy, R. 6A-O-p-Toluenesulfonyl- $\beta$-Cyclodextrin. Org. Synth. 2000, 77, 225, doi:10.15227/orgsyn.077.0225.

37. Muderawan, I.W.; Ong, T.T.; Chia Lee, T.; Young, D.J.; Ching, C.B.; Choon Ng, S. A reliable synthesis of 2- and 6-amino- $\beta$-cyclodextrin and permethylated-b-cyclodextrin. Tetrahedron Lett. 2005, 46, 7905-7907.

Sample Availability: Samples of the compounds CD5 and CD6 are available from the authors.

(C) 2015 by the authors; licensee MDPI, Basel, Switzerland. This article is an open access article distributed under the terms and conditions of the Creative Commons Attribution license (http://creativecommons.org/licenses/by/4.0/). 